\section{Spot Tests in Organic Analysis}

By Dr. Fritz Feigl. Translated by Dr. Ralph E. Oesper. Fifth, enlarged and revised English edition. Pp. $x x+616$. (Amsterdam: Elsevier Publishing Company; London: Cleaver-Hume Press, Ltd., 1956.) 55s.

T $N$ the earlier editions of Prof. Feigl's texts on spot tests, organic reactions were treated as supplementary to inorganic reactions ; later his studies in the organic field led to the appearance in 1954 of Vol. 2 of "Spot Tests", dealing with reactions for qualitative organic analysis. The present edition, the fifth, now appears as a book in its own right and contains much new material.

Prof. Feigl rightly points out that information regarding interferences that may suppress or confuse a test for an organic compound or group is often lacking, and that the degree of reliability is less than in inorganic analysis. He appeals for a scientific approach, rather than an unintelligent use of a 'collection of recipes'. More than one-quarter of the contents of the present volume is occupied by the chapter on the detection of functional groups. Some classical tests are included, and the nitroprusside test for ketones provides a good example of the critical treatment evident throughout the book : the nitroprusside reaction is now stated to be due to the isonitrosation of $\mathrm{CH}_{2}-$ groups and not characteristic of methyl ketones. Subsequent chapters deal at greater length than in the earlier edition with the identification of individual organic compounds and the application of spot tests for technical purposes, including the identification of medicinals and antibiotics.

C. O. HARVEY

\section{Progress in Radiobiology}

Proceedings of the Fourth International Conference on Radiobiology held in Cambridge during 14-17 August, 1955. Edited by Joseph S. Mitchell, Barbara E. Holmes and Cyril L. Smith. Pp. xii +557. (Edinburgh and London: Oliver and Boyd, Ltd., 1956.) 63s. net.

THE chapters of this book give evidence of the wide range of disciplines which are successfully applied in radiobiological research. After a lucid introduction to radiochemical thinking, showing how free radicals formed very closely together can be intercepted by organic molecules, the Conference discussed our knowledge of physical and chemical events following the absorption of ionizing radiations of different linear energy transfer. In general, the chemical efficiency of radiation decreases, while its biological efficiency increases, with increasing linear ion density. A series of papers dealt with the effects of small doses on substances of biological interest and on the metabolism of single cells or whole organisms. The problem of chemical protection appears to become more of a physiological question, involving changes in the oxygen supply to tissues. The 'oxygen effect', the effects on bone and radiation carcinogenesis still offer a wide range of fundamental questions, but have already proved of practical importance in radiotherapy. Human data were analysed both statistically and in detail for individual observations of radium-poisoning. They should be read as a waming against the indiscriminate use of X-ray sets and of radioactive material. Genetic studies are slowly elucidating the topical problem of radiation effects on large breeding populations of bacteria and insects as well as those of plants and mice. The chapter on studies of spleen, bone marrow and blood is of very special interest since we witness the last stages of the controversial question : Which of the elements of the hæmopoietic tissue are the responsible agents for protection against total body irradiation? 'The book is well produced, and it is to the editors' credit that much of the spontaneity of the recorded discussion has been preserved.

M. EBeRT

\section{Aberrations of Thin Lenses}

An Elementary Treatment for Technicians and Students. By H. H. Emsley. Pp. xvi+352. (Lon. don : Constable and Co., Itd., 1956.) 50s. net.

A NUMBER of the older English works on aberration theory were restricted to a treatment using only elementary mathematics; this tradition is continued here, following in general Conrady's methods. Some knowledge of elementary optics is assumed, and the book is mainly concerned with the primary aberrations of thin lenses, leading up to the design of an objective and simple eyepiece for a prism binocular, and a thorough discussion of spectacle lenses. The presentation is clear, worked examples being given at each stage. The use of only elementary algebra, geometry and trigonometry involves loss of brevity and greatly restricts the scope of the work; thus the formulæ for the primary aberrations of oblique imagery are quoted but not derived, and though there is a short chapter on aspheric surfaces, the primary aberrations of these are not treated. The extent to which a technician with very limited mathematical knowledge is likely to be concerned with lens designing is perhaps debatable; certainly for a university student one of the rather more advanced text-books would be preferable.

The book contains a number of mistakes: for example, the coma diagram (p. 165) is wrong; the statement on pp. 71 and 203 that no shape of thin lens reduces the primary spherical aberration to zero is incorrect for a range of virtual object or image positions ; normal eyepieces, including that designed in the text, do not have over-corrected primary field curvature, as suggested on p. 214. It is surely misleading to quote Maxwell's definition of a perfect optical instrument (p. 145) without adding that he proved it could not exist except in the case of a telescope of unit magnification. C. G. WYNNE

\section{Physics}

By S. G. Starling and Prof. A. J. Woodall. Second edition. Pp. xvi $+1328+11$ plates. (London and New York : Longmans, Green and Co., Ltd., 1957.) 55s. net.

COME rewriting, a certain amount of new matter, $\checkmark$ a list of suggestions for further reading, and numerous additional examples for solution are the chief alterations made for the second edition of this excellent and well-established text-book. While small in themselves, these changes should add considerably to the book's usefulness as a sheet-anchor for students taking the less-specialized kind of degree course in physics, and lend some weight to the suggestion that boys might profitably use it for scholarship work at school. There is some sound advice both in the preface and in the reading list, and the student who masters the contents of the book and acquires its outlook will be well equipped indeed.

G. R. NOAKES 